\title{
Determination of Ethyl Vanillin by a Using Briggs-Rauscher Oscillator
}

\author{
Waqar Uddin ${ }^{1}$, Gang Hu ${ }^{1, *}$, Lin Hu$^{2}$, Xiaofeng Shen ${ }^{1}$, Zhaohui Fang ${ }^{3}$, Yu Zhang ${ }^{1}$, and Jimei Song ${ }^{1}$ \\ ${ }^{1}$ Department of Chemistry, Anhui University, Hefei, 230601, People's Republic of China \\ ${ }^{2}$ Institute of Applied Chemistry, East China Jiaotong University, Nanchang, 330013, People's \\ Republic of China \\ ${ }^{3}$ The First Affiliated Hospital of Anhui University of Chinese Medicine, Hefei, 230031, People's \\ Republic of China \\ *E-mail: hugang@ustc.edu
}

doi: $10.20964 / 2017.01 .51$

Received: 22 July 2016 / Accepted: 19 October 2016 / Published: 12 December 2016

\begin{abstract}
A study on the determination of an antioxidant ethyl vanillin (EV) built on its perturbation effects on a Briggs-Rauscher (BR) oscillator was reported in this paper. A tetraazamacrocyclic Ni(II) complex, $[\mathrm{NiL}]\left(\mathrm{ClO}_{4}\right)_{2}$, was used as a catalyst in such a oscillator, and the ligand $\mathrm{L}$ in the complex is 5,7,7,12,14,14-hexamethyl-1,4,8,11-tetraazacyclotetradeca-4,11-diene. The $\mathrm{pH}$ value for the $\mathrm{BR}$ reaction was kept at 2 , which is analogous to the $\mathrm{pH}$ of the fluids of the human stomach. It has been concluded from the experimental data that the addition of EV into BR system could cause the temporary cease in the oscillation after inhibition time $\left(\mathrm{t}_{\mathrm{in}}\right)$ depending on the concentration of EV added. It was found that, as the concentration of EV were increased, the $t_{\text {in }}$ were increased. Thus, a polynomial regression curve was achieved over a range $7.5 \times 10^{-6}$ to $3.5 \times 10^{-5} \mathrm{M}$ of EV with a correlation coefficient of 0.98 . The obtained RSD from six measurements of $2.5 \times 10^{-5} \mathrm{M}$ of EV is $0.159 \%$. On the basis of the FCA model, reaction mechanism involving $\mathrm{HOO}^{\circ}$ radical has been proposed.
\end{abstract}

Keywords: Antioxidant; Briggs-Rauscher; Chemical oscillation; Ethyl vanillin; Inhibitory effect

\section{FULL TEXT}

(C) 2017 The Authors. Published by ESG (www.electrochemsci.org). This article is an open access article distributed under the terms and conditions of the Creative Commons Attribution license (http://creativecommons.org/licenses/by/4.0/). 